\title{
PENGEMBANGAN VIDEO TUTORIAL MATERI PASSING SEPAKBOLA MATA PELAJARAN PJOKUNTUK KELAS $X$ SMA/SMK
}

\author{
Elvrado Klemen Simanjorang ${ }^{1}$, Dr. Wahjoedi ${ }^{2}$, Ni Luh Putu Spyanawati ${ }^{3}$ \\ Prodi Pendidikan Jasmani Kesehatan dan Rekreasi \\ Jurusan Pendidikan Olahraga \\ Fakultas Olahraga dan Kesehatan \\ Universitas Pendidikan Ganesha
}

\begin{abstract}
e-mail: elvraldosimanjorang@gmail.com¹,Wahjoedi@undiksha.ac.id ${ }^{2}$, putu.spyanawati@undiksha.ac.id ${ }^{3}$.
\end{abstract}

\begin{abstract}
ABSTRAK
Tujuan dari penelitian ini ialah untuk mengembangkan multimedia berbasis video tutorial teknik dasar passing sepakbola dengan model ADDIE. Jenis penelitian ini adalah penelitian pengembangan. Prosedur pengembangan model ADDIE, yaitu: analysis, design, development, implementation dan evaluation. Teknik analisis deskriptif kualitatif dan analisis deskriptif kuantitatif adalah teknik analisis data yang digunkan. Multimedia interkatif berbasis video tutorial teknik dasar passing sepakbola kaki bagian dalam yang dikembangkan yaitu dalam bentuk video tutorial yang berisikan materi tentang pengertian teknik dasar passing sepakbola dan cara melakukan teknik dasar passing sepakbola dengan kaki bagian dalam. Berdasarkan tanggapan ahli isi mata pelajaran menunjukkan bahwa multimedia berbasis video tutorial teknik dasar passing sepakbola kaki bagian dalam adalah sangat baik dengan persentase $92 \%$. Tanggapan ahli media pembelajaran memperoleh persentase 95\% berada pada kualifikasi sangat baik. Tanggapan ahli desain pembelajaran memperoleh presentase $93 \%$ berada pada kualifikasi sangat baik. Dapat disimpulkan bahwa multimedia interaktif berbasis video tutorial teknik dasar passing sepakbola kaki bagian dalam layak digunakan dalam mata pelajaran pendidikan jasmani olahraga dan kesehatan. Peneliti berharap agar penelitian ini dieksperimenkan sehingga keefektifan dapat diketahui melalui tiga uji yang dilakukan.
\end{abstract}

Kata kunci: multimedia video, passing sepakbola, ADDIE

\section{ABSTRAC}

The purpose of this research is to develop a video-based multimedia tutorial on the basic techniques of football passing with the ADDIE model. This type of research is development research. The ADDIE model development procedure, namely: analysis, design, development, implementation and evaluation. Qualitative descriptive analysis techniques and quantitative descriptive analysis are the data analysis techniques used. Interactive multimedia based on video tutorials on the basic techniques of passing football in the inner foot that was developed in the form of video tutorials which contain material about the understanding of basic soccer passing techniques and how to do basic soccer passing techniques with the inner foot Based on the responses of subject content experts, it shows that multimedia based video tutorials on the basic techniques of passing football in the inner foot are very good with a percentage of 92\%. The response of instructional media experts is that $95 \%$ of them are in very good qualifications. The response of the learning design expert obtained a percentage of $93 \%$ in very good qualifications. It can be concluded that interactive multimedia based on video tutorials on the basic techniques of passing football in the inner foot is suitable for use in sports and health physical education subjects. 
Researchers hope that this research will be experimented with so that its effectiveness can be determined through the three tests carried out.

Keywords: multimedia video, soccer passing, ADDIE

\section{PENDAHULUAN}

Proses pembelajaran adalah suatu proses yang melibatkan interaksi antara pserta didik dan guru maupun antar guru dengan siswa. Dimana dengan adanya interksi ini diharapkan peserta didik dapat memperoleh pemahaman apa yang diperoleh dalam interaksi belaja mengajar. Dalam peroses pelaksaan pembelajaran bangku sekolah ada beberapa faktor yang mempengaruhinya yaitu faktor internal dan faktor eksternal, dan tidak hanya itu saja media ataupun multimedia sangatlah mempengaruhi peroses pembelajaran dalam mencapai hasil belajaran yang maksimal. Maka dari itu diperlukan pengembanganpengembang media ataupu multimedia lainya yang inovatif. Adapun permasalahan yang masih sering terjadi dan ditemui dalam pembelajaran Pendidikan Jasmani Olahraga Dan Kesehatan (PJOK) adalah proses pembelajaran yang bersifat tradisional. Hal ini dapat dilihat dari peroses pembelajaran yang masih dilakukan secara klasikal ataupun kelompak besar dimana peroses pembelajaran dialakukan tanpa memerhatikan karakteristik peserta didik. Hal ini bisa kita lihat berdasarkan data hasil ulangan harian materi bola besar teknik dasar passing (sepakbola) masih banyak peserta didik kelas $X$ SMK Negeri Singaraja Tahun Pelajaran 2020 memenuhi kereteria maksimal (KKM) 75 yang berlaku. Kelas $X$ Negeri 1 Singaraja terdapat 12 kelas yang terdiri dari 444 peserta didik. Jadi jumlah peserta didik yang tuntas dalam materi passing kaki bagian dalam $17,1 \%$ dan yang tidak tuntas $82,9 \%$. Rendah hasil belajar tersebut dikarenakan perose pembelajaran yang masih berpusat pada guru (tradisional) dan pengembang media atau multimedia pembelajaran masih minim digunakan dalam membuat aktivitas pembelajaran mudah dipahami. Oleh sebab itu, peran guru dalam mengembengkan multimedia pembejaran berbasis video sangatlah membantu pesrta didik karena semua kegiatan belajar mengajar dilakukan secara jarak jauh atau melalui media virtual (daring). Sehingga membuat peserta didik lebih mudah memahami materi yang diberikan melalui media virtual ataupun daring. Fungsi media pembelajaran adalah sebagi alat perantara yang memudahkan dalam mengajar, yakni menunjang penggunaan metode mengajar yang diterapkan maupun yang digunakan oleh guru dalam mengajar. Agar lebih menyenangkan, maka guru dapat mengemas materi menjadi sebuah bahan ajar yang lebih menarik, dengan mengaplikasikan teknologi dalam dunia pendidikan. Berdasarkan permasalahan di atas maka penelitian berkeinginan mengangkat yang berjudul pengembangan multimedia interaktif pembelajaran berbasis video tutorial materi passing sepakbola pada mata pelajaran PJOK kelas X SMA Negeri 1 Singaraja tahun pelajaran 2020/2021.

Merujuk dari permasalahan di atas maka penelitian merumuskan masalah yaitu:

1) Bagaimana kelayakan pengembangan multimedia interaktif pembelajaran berbasis video tutorial 
materi passing sepakbola pada mata pelajaran PJOK kelas X SMK Negeri 1 Singaraja?

Adapun tujuan dari penelitian pengembangan ini yaitu:

1) Untuk mendeskripsikan kelayakan pengembangan multimedia interaktif berbasis video tutorial materi passing sepakbola pada mata pelajaran PJOK kelas $X$ SMK Negeri 1 Singaraja.

Menurut Tegeh dan Jampel (2017) "penelitian pengembangan adalah upaya yang mengembangkan dan menghasilkan suatu produk berupa materi, media, alat atau strategi pembelajaran, yang digunakan untuk mengatasi permasalahan pembelajaran di kelas/laboratorium, dan bukan untuk menguji teori”. Penelitian seperti ini akan lebih memfokuskan tujuan untuk menghasilkan dan mengembangkan produk yang layak digunakan sesuai dengan kebutuhan. Menurut Putra (2011) Penelitian pengembangan didefinisikan sebagai metode penelitian yang secara sengaja, sistematis, bertujuan/diarahkan untuk mencaritemukan, merumuskan, memperbaiki, mengembangkan, menghasilkan, menguji keefektifan produk, model, metode/strategi/cara, jasa, prosedur tertentu yang lebih unggul, baru, efektif, efisien, produktif, dan bermakna. Menurut Mulyatiningsih, (2014) penelitian dan pengembangan bertujuan untuk menghasilkan produk baru melalui proses pengembangan. Produk penelitian dan pengembangan dalam bidang pendidikan dapat berupa model, media, peralatan, buku, modul, alat evaluasi dan perangkat pembelajaran. Berdasarkan paparan para ahli di atas, yang dimaksud dengan penelitian pengembangan adalah upaya yang secara sengaja, sistematis, bertujuan/diarahkan untuk mencaritemukan, merumuskan, memperbaiki, mengembangkan, dan menghasilkan, serta menguji keefektifan suatu produk berupa materi, media, alat atau strategi pembelajaran, yang digunakan untuk mengatasi masalah yang ada. Menurut Arsyad (2007) Menjelaskan bahwa, kata media berasal dari bahasa Latin, yaitu medius. Arti kata medius adalah tengah, perantara, atau pengantar. Dalam proses pembelajaran media seringkali diartikan sebagai alat-alat grafis, photografis, atau alat elektronik yang berfungsi untuk menangkap, memproses, dan menyusun kembali informasi visual atau verbal. Menurut Sadiman, (2014) "media segala sesuatu yang dapat digunakan untuk menyalurkan pesan dari pengirim ke penerima sehingga dapat merangsang pikiran, perasaan, perhatian dan minat serta perhatian peserta didik sedemikian rupa sehingga proses belajar terjadi”. Menurut Turmono, (2018). Media pembelajaran dapat diartikan sebagai segala sesuatu yang dapat dipergunakan untuk merangsang pikiran, perasaan, perhatian dan kemampuan atau keterampilan pembelajar sehingga dapat mendorong terjadinya proses belajar. Pembelajaran merupakan proses, cara dan tindakan yang memengaruhi peserta didik untuk belajar. Menurut Wati, (2016) Proses pembelajaran disini ialah perpaduan yang tersusun secara rapi meliputi unsur-unsur manusiawi, material, fasilitas, perlengkapan, dan 13 prosedur yang saling mempengaruhi tercapainya tujuan pembelajaran

Menurut (Rahayu, Dida Firmansyah, (2018). Pembelajaran adalah suatu proses dimana lingkungan seseorang secara sengaja dikelola untuk memungkinkan ia turut serta dalam tingkah laku tertentu dalam kondisi-kondisi khusus atau menghasilkan respon terhadap situasi tertentu. 
Berdasarkan beberapa pendapat di atas maka media pembelajaran adalah segala sesuatu yang dapat digunakan baik berupa alat-alat grafis, photografis, atau elektronik lainnya yang berfungsi untuk menyalurkan pesan dari pengirim (guru) ke penerima (peserta didik) sehingga dapat merangsang pikiran, perasaan, perhatian dan minat serta perhatian peserta didik sehingga proses belajar terjadi dan tujuan pembelajaran tercapai.

Menurut Darma, dkk (2009) menyatakan, multimedia ditinjau dari bahasanya terdiri dari 2 kata, yaitu multi dan media. Multi memiliki arti banyak atau lebih dari satu. Sedangkan media merupakan bentuk jamak dari medium, juga diartikan sebagai saran, wadah, atau alat. Istilah multimedia sendiri dapat diartikan sebagai transmisi data dan manipulasi semua bentuk informasi, baik berbentuk katakata, gambar, video, musik, angka atau tulisan tangan dimana dalam dunia komputer, bentuk informasi tersebut diolah dari dan dalam bentuk data digital. Menurut Wati (2016) "multimedia merupakan perpaduan berbagai bentuk elemen informasi yang digunakan sebagai sarana menyampaikan tujuan tertentu". Elemen informasi yang dimaksud tersebut diantaranya teks, grafik, gambar, foto, animasi, audio, dan video. Menurut (Rimayanti, dkk. 2019: 86). Multimedia merupakan perpaduan antara berbagai media (format file) yang berupa teks, gambar (vektor atau bitmap), grafik, sound, animasi, video, interaksi, dan lain-lain yang dikemas menjadi file digital (komputerisasi), digunakan untuk menyimpan atau menghantarkan pesan kepada publik. Sejalan dengan beberapa pendapat di atas maka multimedia interaktif merupakan media penyampaian yang memanipulasi informasi dalam bentuk digital yang terdiri dari elemen teks, suara, gambar, animasi, dan video secara terpadu dan sinergis dengan bantuan komputer atau sejenisnya untuk mencapai tujuan tertentu yang melibatkan respon pemakai secara aktif.

Menurut (Syuradin, Radiko, 2020: 6). Video tutorial merupakan media proses pembelajaran yang dikemas dalam video dengan tujuan untuk mempermudah siswa dalam memahami pembelajaran.

Menurut (Hikmawati, Sukardi, 2019: 64). Video tutorial merupakan media pembelajaran yang menyampaikan pesan kepada siswa berupa audio dan visual yang di dalamnya terdapat materi pembelajaran interaktif sehingga siswa dapat belajar secara mandiri yang tidak dibatasi dengan tempat.

Menurut Ikrayenti, dkk, (2013). Video tutorial merupakan salah satu jenis dari media berbasis audio-visual3. Video tutorial berasal dari kata video dan tutorial. Menurut Kamus Besar Bahasa Indonesia (KBBI), video (vi.deo) berarti (1) bagian yg memancarkan gambar pada pesawat televisi; (2) rekaman gambar hidup atau program televisi untuk ditayangkan lewat pesawat televisi.

Menurut Mielke, (2007). "Passing adalah seni memindahkan momentum bola dari satu pemain ke pemain lain". Menurut Kusuma (2018). "Mengoper bola (passing the ball) adalah seni memindahkan momentum boal dari satu pemain ke pemain lain". Menerut Luxbacher (2016). "Bola yang sedang menggelinding di atas permukaan lapangan lebih mudah dioper." Menurtut Ngolo (2018). "Passing merupakan salah satu cara memberikan/mengoper bola kepada teman satu tim dengan kaki bagian luar, pungung kaki, dan bisa juga dengan kaki bagian dalam operan ini banyak sekali dimanfaatkan oleh para pemain apa lagi dengan seorang pemain penyerang atau bisa juga pemain galandang penyerang." Menurut Muta'al, Anton Komaini, (2019). "passing merupakan salah satu usaha memindahkan bola dari satu ke tempat lain dengan menggunakan kaki bagian dalam" 
Jadi dapat disimpulkan dari uraian di atas passing adalah suatu perpindahan bola dari satu titik awal ketitik yang mau dituju sehingga bola mengalami perpindahan.

\section{METODE}

Model pembuatan produk dalam penelitian pengembangan ini adalah model ADDIE. Pemilihan model ini didasarkan atas pertimbangan bahwa model ini disusun secara terprogram dengan urutan-urutan kegiatan yang sistematis dalam upaya pemecahan masalah belajar yang berkaitan dengan sumber belajar yang sesuai dengan kebutuhan dan karakteristik pebelajar.

Penelitian pengembangan ini menggunakan dua metode dalam pengumpulan data yaitu (1) pencatatan dokumen dan (2) kuisioner. Angket tersebut berisi item-item terkait dengan multimedia interaktif. Instrumen yang berupa angket digunakan peneliti untuk untuk mengumpulkan data hasil review dari ahli isi bidang studi atau mata pelajaran, ahli desain dan ahli media pembelajaran.

Pada ahikiatnya penelitian pengembangan memakai dua teknik analisi yaitu:

1. Analisis deskriptif kualitatif

Teknik analisis deskriptif kualitatif ini digunakan untuk mengolah data hasil review ahli mata pelajaran, ahli desain mata pelajaran, ahli media pembelajaran dan uji coba siswa. Teknik analisis data ini dilakukan dengan mengelompokkan informasi dari data kualitatif yang berupa masukan, tanggapan, kritik, dan saran perbaikan yang terdapat pada angket. Hasil analisis ini kemudian digunakan untuk merevisi produk yang dikembangkan.

\section{Analisis deskriptif kuantitatif}

Teknik analisis ini digunakan untuk mengolah data yang diperoleh melalui angket dalam bentuk deskriptif persentase. Rumus yang digunakan untuk menghitung persentase dari masing-masing subyek adalah sebagai berikut.

Menurut Mulyatiningsih, (2014). Model ADDIE dikembangkan oleh Dick and Carey (1996) untuk merancang sistem pembelajaran.

1. Tahap Analisis (Analyze)

- Hal ini dapat dilihat dari peroses pembelajaran yang masih dilakukan secara klasikal ataupun kelompak besar dimana peroses pembelajaran dialakukan tanpa memerhatikan karakteristik peserta didik. Hal ini bisa kita lihat berdasarkan data hasil ulangan harian materi bola besar teknik dasar passing (sepakbola) masih banyak peserta didik kelas $X$ SMK Negeri Singaraja Tahun Pelajaran 2020 memenuhi kereteria maksimal (KKM) 75 yang berlaku. Kelas $X$ Negeri 1 Singaraja terdapat 12 kelas yang terdiri dari 444 peserta didik. Jadi jumlah peserta didik yang tuntas dalam materi passing kaki bagian dalam $17,1 \%$ dan yang tidak tuntas $82,9 \%$. Rendah hasil belajar tersebut dikarenakan perose pembelajaran yang masih berpusat.

2. Tahap Perencanaan (Design)

Pada tahap ini peneliti merancang produk yang ditujukan untuk peserta didik Kelas X B Akutansi Keuangan di SMK 1 Singaraja tahun pelajaran 2020/2021 dengan pemilihan materi ajar sepakbola Passing pada mata pelajaran Pendidikan Jasmani, Olahraga dan Kesehatan (PJOK).

\section{Tahap \\ Pengembangan (Development)}

Pada tahap ini, hal yang dilakukan adalah mengembangkan produk berupa multimedia interaktif berbasis video tutorial. Pengembangan produk ini adalah pengumpulan bahan dan materi ajar yang diperlukan untuk membuat produk seperti materi pokok (substansi mata pelajaran), aspek pendukung seperti gambar, animasi, audio, video sebagai ilustrasi, clip-art image, dan grafik. Pengembangan materi pokok dilakukan dengan menggunakan buku paket yang didapatkan di sekolah bersangkutan 
dengan mata pelajaran PJOK kelas X di SMK Negeri 1 Singaraja dan buku sumber lain relevan dengan materi kesehatan pada mata pelajaran PJOK kelas $X$. Sedangkan pengumpulan gambar, audio, dan animasi diperoleh melalui pembuatan sendiri, arsip pribadi, dan download melalui internet serta pengambilan langsung di lapangan.

4. Tahap

Implementasi

(Implementation)

Implementasi merupakan langkah nyata untuk menerapkan multimedia interaktif yang sedang dibuat. Artinya pada tahap ini semua yang telah dikembangkan akan diinstal atau diset sedemikian rupa sesuai dengan peran atau fungsinya agar bisa diimplementasikan.

5. Tahap Evaluasi (Evaluation)

Tahap evaluasi bertujuan untuk melihat sejauh mana produk yang dibuat dapat mencapai sasaran dan tujuan yang sudah ditetapkan sebelumnya. Pada tahap ini dilakukan penilaian terhadap media yang dihasilkan dari validitas tiga ahli yaitu ahli isi, ahli media pembelajaran, dan ahli desain pembelajaran. Masing-masing ahli akan diberikan kuisioner/angket penilaian sesuai dengan bidang keahliannya. Setelah dilakukan revisi, maka uji coba selanjutnya akan dilakukan uji coba perorangan, uji coba kelompok kecil, dan uji coba lapangan.

\section{HASIL DAN PEMBAHASAN}

Berdasarakan hasil observasi di SMK Negeri 1 Singaraja masih tergolong rendah, peneliti mendapatkan kesenjangan terhadap proses pembelajaran yang dilaksanakan yaitu, Permasalahan yang masih sering terjadi dan ditemui dalam pembelajaran Pendidikan Jasmani Olahraga Dan Kesehatan (PJOK) adalah proses pembelajaran yang bersifat tradisional. Hal ini dapat dilihat dari peroses pembelajaran yang masih dilakukan secara klasikal ataupun kelompak besar dimana peroses pembelajaran dialakukan tanpa memerhatikan karakteristik peserta didik, rendahnya hasil belajar dan kurang optimalnya pemakaian saran dan media seperti LCD dan yang lainnya. Oleh sebab itu, peran guru dalam mengembengkan multimedia pembejaran berbasis video sangatlah membantu pesrta didik karena semua kegiatan belajar mengajar dilakukan secara jarak jauh atau melalui media virtual (daring). Sehingga membuat peserta didik lebih mudah memahami materi yang diberikan melalui media virtual ataupun daring.

Tabel 1. Hasil Uji Para Ahli

\begin{tabular}{clll}
\hline No & Ahli & Presentasi & Kualifikasi \\
\hline 1 & $\begin{array}{l}\text { Ahli Mata } \\
\text { Pelajaran }\end{array}$ & $92 \%$ & Sangat Baik \\
2 & $\begin{array}{l}\text { Ahli Desain } \\
\text { Pelajaran }\end{array}$ & $93 \%$ & Sangat Baik \\
3 & $\begin{array}{l}\text { Ahli Media } \\
\text { Pelajaran }\end{array}$ & $95 \%$ & Sangat Baik \\
\hline
\end{tabular}

Setelah data tersebut dikonversikan dengan tabel konversi skala 5 diperoleh hasil persentase yaitu $92 \%$ berada, pada, kualifikasi Sangat Baik. Dengan demikian media pembelajaran berbasis video tutorial ini memiliki tingkat kelayakan Sangat Baik dari aspek materi. Adapun komentar, masukan, tanggapan, kritik dan saran mengenai multimedia interaktif berbasis video tutorial materi teknik dasar passing sepakbola kaki bagian dalam yang diberikan oleh ahli isi/materi dipaparkan pada. 1) Kejalasan informasi, 2) Pada ilustrasi gambar di perbaiki lagi agar 
tulisan tidak tertutupi media, sehingga yang mengamati lebih fokus.

Setelah data tersebut dikonversikan dengan tabel konversi skala 5 diperoleh hasil persentase yaitu $93 \%$ berada pada kualifikasi Sangat Baik. Dengan demikian media pembelajaran berbasis video tutorial ini memiliki tingkat kelayakan Sangat Baik dari aspek desain media. Adapun komentar, masukan, tanggapan, kritik dan saran mengenai multimedia interaktif berbasis video tutorial materi teknik dasar passing sepakbola kaki bagian dalam yang diberikan oleh ahli isi/materi dipaparkan pada. 1) Isi judul video, 2) Sajikan simpulan singkat diakhir, 3) Isi tim kerabat kerja produksi seperti Dosen, dll, 4) Tipografi atau huruf pada indikator agar dirapikan

Setelah data tersebut dikonversikan dengan tabel konversi skala 5 diperoleh hasil persentase yaitu 95\% berada pada kualifikasi Sangat Baik. Dengan demikian media pembelajaran berbasis video tutorial ini memiliki tingkat kelayakan Sangat Baik dari aspek ahli media. Adapun komentar, masukan, tanggapan, kritik dan saran mengenai media video pembelajaran materi teknik dasar passing sepakbola kaki bagian dalam yang diberikan oleh ahli isi/materi. 1) Pada intro gambar sudah sangat bagus, tambahkam Prodi, "Mempersembahankan lanjut Judul", 2) Pada ending buat kerabat kerja dan ucapan terima kasih secara singkat, 3) Indikator 1 tidak perlu karena bukan dibuat oleh pengembang, tetapi telah ada dan dibuat pusat kurikulum.

Sedangkan uji coba perorangan, uji coba kelompok kecil dan uji coba kelompok besar tidak dapat dilaksanakan karena adanya Pandemi covid 19 yang mengharuskan peserta didik untuk belajar di rumah secara daring/online.

Tabel 2. Konversi Tingkat Pencapaian Dengan Skala 5 No Tingkat pencapaian Kualifikasi

\begin{tabular}{lcc}
\hline 1 & $90 \%-100 \%$ & Sangat Baik \\
$\mathbf{2}$ & $75 \%-89 \%$ & Baik \\
$\mathbf{3}$ & $65 \%-74 \%$ & Cukup \\
$\mathbf{4}$ & $55 \%-64 \%$ & Kurang \\
$\mathbf{5}$ & $0 \%-54 \%$ & Sangat Kurang \\
\hline
\end{tabular}

\section{KESIMPULAN}

Simpulan penelitian pengembangan ini yaitu, sebagai berikut:

1. Rancang bangun pengembangan ini menggunakan model ADDIE dengan tahapannya yaitu (1) analisis, perancangan, (3) pengembangan, (4) implementasi, dan (5) evaluasi. Dari tahapan tersebut menghasilkan storyboard dan flowchart sebagai dasar pengembangan produk multimedia berbasis video tutorial pada materi teknik dasar passing sepakbola.

2. Validitas menurut para ahli terhadap pengembangan media video pembelajaran yang dikembangkan adalahVsebagaiVberikut: (1) menurut ahli isi mata pelajaran memperoleh presentase $92 \%$ dengan kualifikasi sangat baik, (2) menurut ahli media pembelajaran memperoleh presentase 95\% dengan kualifikasi sangat baik, (3) menurut ahli desain pembelajaran memperoleh presentase 94\% dengan kualifikasi sangat baik.

Sedangkan uji coba perorangan, uji coba kelompok kecil dan uji coba kelompok besar tidak dapat dilaksanakan karena adanya Pandemi covid 19 yang mengharuskan peserta didik untuk belajar di rumah secara daring/online. Sehingga penelitian ini dilaksanakan hanya sampai uji coba ahli saja.

UCAPAN TERIMA KASIH 
Dalam proses pembuatan skripsi ini, sangat banyak mendapat bantuan dari berbagai pihak. Oleh karena itu, pada kesempatan ini diucapkan terimakasih yang sebesar-besarnya dan setulustulusnya kepada yang terhormat:

1. Prof. Dr. I nyoman Jampel, M.Pd., Rektor universitas Pendidikan Ganesha yang telah memberikan kesempatan kepada peneliti untuk mengikuti pendidikan pada Program Studi Pendidikan Jasmani Kesehatan Dan Rekreasi Fakultas Olahraga Dan Kesehatan.

2. Dr. H. Wahjoedi. M.Pd., selaku Dekan Fakultas Olahraga dan Kesehatan sekaligus pembimbing I yang telah memberikan bimbingan, motivasi, saran dan masukan dalam penyelesaian skripsi ini.

3. Ni Luh Putu Spyanawati. S.Pd., M.Pd., selaku Koordinator Program Studi Pendidikan Jasmani, Kesehatan dan Rekreasi sekaligus sebagai pembimbing II yang telah memberikan bimbingan, motivasi, saran dan masukan dalam penyelesaian skripsi ini.

4. Seluruh staff dosen dan pegawai di Fakultas Olahraga dan kesehatan yang telah memberikan pengetahuan dan membantu kelancaran penelitian ini.

5. Keluarga besar yang telah memberikan dorongan secara moril dan materu sehingga skripsi in dapat diselesaikan

6. Semua pihak yang tidak dapat peneliti sebutkan satu persatu yang telah banyak memberikan bantuan dalam penelitian ini.

\section{DAFTAR PUSTAKA}

Arsyad, Azhar. 2007. Media Pembelajaran. Jakarta: PT Raja Grafindo Persada

Anin, Moh. 2013. "Penelitian Pengembangan Dalam Pembelajaran Bahasa Arab". OKRA. Universitas Negeri Malang. Vol 2, HIm 97.
Baharun, Hasan. (2015). Penerapan Pembelajaran Active Learning Untuk Meningkatkan Hasil Belajar Siswa Di Madrasah. PEDAGOGIK: Jurnal Pendidikan. Volume 01 No. 1

Binanto, Iwan. 2010. Multimedia Digital - Dasar Teori dan Pengembangannya.

Yogyakarta: C.V Andi Offset

Bustanil, dkk (2019). "Penelitian Dan

Pembahasan Tentang,

Pengembangan Media

Pemebelajaran Interktif

Berbasis Video Tutorial Di

Sekolah Menengah Kejuruan". Jurnal Teknologi Pendidikan. Universitas Negeri Jakarta. Vol 21, No.2. HIm 132.

Kusuma, Ketut Chandra Adinata, 2018. Kepelatihan Sepak Bola Teori dan Praktik. Depok. RajaGrafindo Persada.

Munir. 2012. Multimedia Konsep \& Aplikasi dalam Pendidikan. Bandung: Alfabeta

Putra, Artanayasa, dkk. (2017). "Pengaruh Penerapan Model Pembelajaran Kooperatif Tipe Student Teams Achievement Division Berbantuan Media Gambar Terhadap Hasil Belajar Passing Sepakbola". E_Journal Pendidikan Jasmani, Kesehatan dan Rekreasi Fakultas Olahraga dan Kesehatan, Undiksha, Volume 8, Nomor 2.

Putra, Nusa. 2011. Research \& Development Penelitian dan Pengembangan: Suatu Pengantar. Jakarta: Rajawali Pers

Rusman, dkk. 2015. Pembelajaran Berbasis Teknologi Informasi dan Komunikasi. Jakarta: Rajawali Pers

Sokheh, dan Wahjoedi. (2017). "Pengembangan Media Video Pembelajaran Dengan Model Addie Materi Passing Bola Basket". E-Journal PJKR, Universitas Pendidikan 
Ganesha Pendidikan Jasmani, Kesehatan, dan Rekreasi. Vol 8, No.2.

Tatang Suryadin dan Radiko (2020). "Pengaruh Penerapan Media Pembelajaran Video Tutorial Terhadap Peningkatan Kemampuan Teknik Dasar Tendangan Depan Pencak Silat". Research Physical Education and Sprots. Universitas Majalengka. Vol 2, No. 1. HIm 5.

Tegeh, I Made dan I Nyoman Jampel. 2017. Metode Penelitian Pengembangan. Singaraja: Undiksha. 